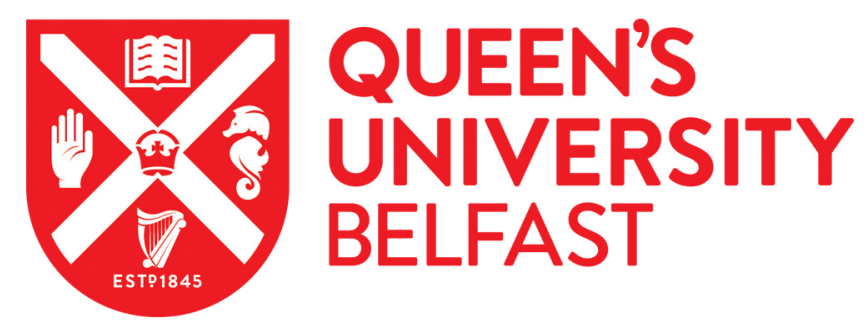

\title{
Pilot feasibility study of the Walking Away from Diabetes program for adults with intellectual disabilities in two further education colleges: Process evaluation findings
}

Maine, A., Brown, M., Dickson, A., \& Truesdale, M. (2019). Pilot feasibility study of the Walking Away from Diabetes program for adults with intellectual disabilities in two further education colleges: Process evaluation findings. Journal of Applied Research in Intellectual Disabilities. https://doi.org/10.1111/jar.12593

Published in:

Journal of Applied Research in Intellectual Disabilities

Document Version:

Peer reviewed version

Queen's University Belfast - Research Portal:

Link to publication record in Queen's University Belfast Research Portal

Publisher rights

Copyright 2019 Wiley. This work is made available online in accordance with the publisher's policies. Please refer to any applicable terms of use of the publisher.

\section{General rights}

Copyright for the publications made accessible via the Queen's University Belfast Research Portal is retained by the author(s) and / or other copyright owners and it is a condition of accessing these publications that users recognise and abide by the legal requirements associated with these rights.

\section{Take down policy}

The Research Portal is Queen's institutional repository that provides access to Queen's research output. Every effort has been made to ensure that content in the Research Portal does not infringe any person's rights, or applicable UK laws. If you discover content in the Research Portal that you believe breaches copyright or violates any law, please contact openaccess@qub.ac.uk. 


\title{
Pilot feasibility study of the Walking Away from Diabetes program for adults with ID in two further education colleges: Process evaluation findings
}

\author{
Andrew Maine ${ }^{1}$, Michael J. Brown ${ }^{1}$, Adele Dickson ${ }^{2}$, Maria Truesdale ${ }^{3}$
}

1: Queen's University Belfast, School of Nursing and Midwifery, Belfast, UK; 2: Glasgow Caledonian University School of Health and Life Sciences, Glasgow, Glasgow, UK; 3: Edinburgh Napier University, Edinburgh Napier University School of Health and Social Care, 9 Sighthill Court, Edinburgh, UK EH114BN

Corresponding author: A.maine@qub.ac.uk

\begin{abstract}
Background: People with intellectual disabilities (ID) remain at high risk of developing type 2 diabetes (T2D) due to lifestyle associated risk factors. Educational programs have been adapted for people with ID targeting ongoing T2D self-management. However, there are no adapted programs which aim to prevent T2D through reducing risk factors. The present study initiates addressing this gap.

Methods: Further education (FE) Colleges in Scotland were recruited for feasibility study using the Walking Away (WA) from Diabetes program. Process evaluation assessed recruitment, retention, baseline physical activity levels, and acceptability and accessibility using focus groups
\end{abstract}


Results: $96 \%$ of invited students agreed to participate. WA was positively received, and some short-term impact was described. Suggestions for further adaptations regarding materials, delivery, and content were provided, including delivery embedded within FE college curriculum.

Conclusions: Recruitment, retention, and acceptability provide rationale for further research on T2D prevention in FE colleges. 


\section{Introduction}

People with intellectual disabilities (ID) are at greater risk than the general population of developing chronic diseases due to limited health literacy, poor diet, low levels of physical activity, and sedentary behaviour (Emerson and Baines, 2010, Melville et al., 2015, Taggart et al., 2013). A disease associated with these behaviours is type 2 diabetes (T2D), an instability of blood sugar levels due to low or ineffectively used insulin, which can lead to cardiovascular complications and a range of circulatory problems, reducing life expectancy by up to ten years and affecting over 400 million people in the world (Diabetes UK, 2017).

To address this global epidemic, mainstream self-management programs have been developed which target lifestyle change through structured education, such as DESMOND (Diabetes Education and Self-management for Ongoing and Newly Diagnosed), developed by Davies et al. (2008). Until recently, there was a dearth of programs tailored to the needs of people with ID. However, a feasibility trial of an adapted version of DESMOND was conducted by Taggart et al. (2017), which reported significant reductions in blood sugar levels together with focus group feedback indicating acceptability to people with ID and their caregivers. A trial protocol has been reported for a second self-management program, OK Diabetes, also aimed at people with ID and caregivers, delivered in a primary care setting (Walwyn et al., 2015).

These programs begin to address the needs of people with ID who have been diagnosed with T2D. It has also been recognised that structured education can reduce risk factors and prevent the onset of T2D. Structured education programs can equip people with a range of skills and knowledge, including awareness of risks, causes, and consequences, together with dietary and physical activity benefits. A review systematic review highlighted that many of these programmes lead to significant changes in health literacy and 
subsequently to healthier lifestyles Maine et al. (2018a). This review also identified seven mainstream preventative programs since 2005 (Contento, Koch, Lee, and Calabrese-Barton, 2010; Heideman et al., 2015; Laatikainen et al., 2007; McCurley et al., 2017; 2010; Sacco, Malone, Morrison, Friedman, and Wells, 2009; Yates et al. 2009; Yates et al., 2016) which reported significant changes in blood sugar levels, physical activity, dietary habits and knowledge, and Self-efficacy. These outcomes were achieved through physical activity and dietary education, together with goal setting and resiliency training underpinned by Social Cognitive Theory (Bandura, 1977) and Leventhal's Self-Regulatory Theory (Leventhal, 1980). Such lifestyle changes reportedly reduce the risk of T2D by up to $60 \%$ (Gillies et al., 2007), and it may therefore be beneficial to explore these components in relation to people with ID at risk of T2D.

Studies reporting the T2D self-management experiences of people with ID found that changes to lifestyle following diagnosis were met with frustration, and adjustment was challenging (Maine et al., 2018b). Living situations also contributed to this frustration, as social comparisons were made with peers with ID who did not have T2D. This limits opportunity for Bandura's (1977) "vicarious experience", where Self-efficacy can be enhanced through socially modelling peers. Additionally, further staff training, and resources were required in order to support people with ID to self-manage independently. It can be concluded from these findings that early intervention is important, as is the supportive environment in which interventions are delivered. Prevention programs aimed at people with ID should therefore target younger age groups so that healthy lifestyles can be established early, and a supportive environment where behaviours can be supported and reinforced should be considered. 
An environment which could potentially provide this support is in further education (FE) colleges. Faro et al. (2005) and Saksvig et al. (2005) delivered programs within an educational curriculum, where it was possible to reinforce health messages and provide high social support. In Scotland, six\% of the adult ID population were in further education during 2017 , and $94.4 \%$ of these adults were aged 16-34 and attended at least three days per week (Scottish Commission of Learning Disabilities, 2017). Therefore, there is a rationale for assessing the feasibility of delivering a T2D structured educational program for people with ID in this setting.

A review by Scott and Havercamp (2016) highlighted there have been several non T2D specific programmes which target behavioural change in people with ID. However, with the exception of one study (Hinkson et al. 2013), which specified the age of children as over seven, mean or range of ages of participants were not provided. It is therefore unclear from Scott and Havercamp (2016) the extent to which preventative programmes have been aimed at younger adults or adolescents with ID. Dunkley et al. (2017) has recently undergone a successful pilot trial delivered in a primary care setting, and qualitative data suggests that a randomized controlled trial is appropriate. However, prior to the present study, no preventative programs have been explored within an FE college setting for people with ID, where there may be opportunities for supported attendance and adherence to a programme. The present study addresses this gap by carrying out a process evaluation of the Walking Away program within two further education colleges in Scotland. The aim was to assess the feasibility of recruiting for and delivering the programme in this setting, and to qualitatively assess its acceptability and accessibility through focus groups.

\section{Methods}


The process evaluation of WA used the updated Medical Research Council guidelines (Moore et al., 2014). The evaluation comprised of recruitment, implementation, acceptability and accessibility. Figure 1 below presents Moore et al.'s (2014) functions and stages of a process evaluation model, adapted for the present study. The MRC model highlights fidelity, the extent to which core values and philosophies are retained in implementation, as a mechanism of impact to be evaluated. However, the values of WA are drawn from the DESMOND program (Davies, 2008); as the fidelity of an adaptation of DESMOND for people with ID was evaluated by Taggart et al., (2017), it was not necessary to repeat this measure. Instead, the focus was on the accessibility and accessibility of the delivery, study process, and materials, to students with ID in a further education setting.

\section{Insert Figure 1 here}

\subsection{Intervention}

Walking Away from Diabetes (WA) is a three-hour structured educational program which was developed for adults without ID who have T2D risk factors. The programme aims to increase physical activity, and is adapted from the DESMOND (Diabetes Self-management for Ongoing and Newly Diagnosed) (Davies, 2008) and PREPARE (Yates, 2009) programs. A strong theoretical basis includes Social Cognitive Theory (Bandura, 1977), Leventhal's Self-regulation Model (Leventhal, 1980), and Dual Processing Theory (Chaiken, 1987). The program is comprised of four major components, including knowledge of glucose metabolism, knowledge of T2D risks, knowledge and goal setting for physical activity, and awareness of saturated fats. Sessions are delivered using pictorial aids, role play, and analogies. Pragmatic adaptations were made to the programme, which primarily included the 
length and division of sessions. These were made in consultation with the programme trainers and the FE college lecturers. It was anticipated that the focus groups would identify any further adaptations for subsequent trials of the programme in this setting.

\subsection{Recruitment and procedure}

Further education colleges were contacted by email and phone, and 2/7 agreed to participate. Both sites indicated that approximately 25-30 participants would be likely to participate. During these discussions, the 3-hour duration of the program was deemed to be unsuitable for the students, whose lessons were typically 1 to 1.5 hours. Therefore, the program was comprised of four parts of 45 minutes to 1 hour in length.

Recruitment of student participants began at the start of the first trimester, in September 2016. The researcher gave a verbal presentation of the study which described consent, an overview of WA, and the measures. An accessible information pack was handed out. It was emphasised that participation was optional. To ensure voluntary consent, lecturers added that alternative activities would be available, such as computer time.

Focus group recruitment took place following the WA delivery. Lecturing staff were invited to participate in separate focus groups. Due to the distance between the two study locations, focus groups took place at each site. Kaehne and O'Connell's (2010) guidelines for planning and conducting focus groups with people with ID were adopted. Eight student participants and four lecturers per site were selected. The focus groups lasted approximately one hour and took place in college classrooms. Topics covered each of the units, the overall delivery and materials, recruitment and consent, and the pedometers. The groups were audio recorded and transcribed verbatim. 


\subsection{Ethics}

Ethical approval for this study was obtained through Edinburgh Napier University Research Governance Committee. All participants could provide signed consent. Participant names were transcribed as pseudonyms and identifying details were removed. As an additional consideration, lecturing staff had been alerted to the potential distress of identifying risk factors and had agreed with the researcher to signpost to local GPs for further information and support.

\subsection{Baseline Measures}

Baseline data were obtained one month prior to delivery of the WA programme. The aims of collecting these measures were to assess the feasibility of using the same measures used in the mainstream WA study (Yates et al., 2016), and to provide an account of the level of physical activity the participants engaged in, thus providing an indication of the appropriateness of the sample for intervention. The International Physical Activity Questionnaire (IPAQ) asked participants about their physical activity across contexts. A pilot study by McKeon, Slevin and Taggart (2013) confirmed the IPAQ as a practical tool to use with people with ID in conjunction with measures of physical activity. Since this study was conducted, the IPAQ has been adapted and validated for people with ID in the DESMONDID study (Taggart et al., 2017). The present study evaluated the process for replicating the mainstream WA trial (Yates et al. 2016) for people with ID in the context of further education, using the IPAQ without adaptation. Therefore, the results consider the strengths and limitations of this measure prior to adaptation. 
Ambulatory activity was recorded using the Yamax SW-200 pedometer, a well validated and cost-effective model (Schneider, 2003). Data were collected via self-report, which provided an indication of the usability of the pedometers, and of the students' ability to record and report readings. A minimum of three days per week were measured, as recommended by Temple and Stanish (2009).

A second aim was to further describe the level of the participants' ambulatory activity by providing a mean weekly step count. Temple and Stanish (2009) reported an average step count of 6508 steps per day (SD 3296) in adults with ID. This number was used to predict the sample in the trial of "Walk Well" (Melville et al., 2015) and provides a point of comparison for the present study.

\section{Results}

Results are presented in accordance with the "Mechanisms of impact" section, within the MRC model illustrated in Figure 1, page 4.

Sample size and demographic

Although only $29 \%$ of colleges responded to initial recruitment contact, a total of $48 / 50$ students agreed to participate. There were 18 (37.5\%) female participants and 30 (62.5\%) male. The age range was 18-39 years, mean 20.9 (SD 5.02). The mean female age was 22.7 (SD 7.5), male 19.9 (SD 2.3). Table 1, provides an overview of the student demographics. 
Insert Table 1 here

\subsection{Baseline measures}

\subsubsection{Physiological}

Overall weight ranged from $53-124 \mathrm{~kg}$, mean $81.6 \mathrm{~kg}$ (SD 22.7). The mean female weight was 79.2kg (SD 21.9), male $83 \mathrm{~kg}$ (SD 23.4). The overall waist circumference ranged from 54$161 \mathrm{~cm}$, mean $98.3 \mathrm{~cm}$ (SD 21.3). The mean female was waist circumference was $96.8 \mathrm{~cm}$ (SD 30.5), male 96.9 (SD 20.1). The mean BMI was 33.3 (obese) for females and 27.1

(overweight) for males. Seventeen $(37.5 \%)$ of the participants were in the obese category. Ten $(59 \%)$ of these were female and seven $(41 \%)$ were male. $12(25 \%)$ of the participants were in the overweight category. Three $(25 \%)$ of these were female and nine $(75 \%)$ were male. 15 of the participants were in the healthy weight category. Four $(27 \%)$ of these were female and $11(73 \%)$ were male. Three of the participants were underweight, all of these were male.

\subsubsection{Physical activity}

\subsubsection{International physical activity questionnaire}

Physical activity knowledge and beliefs is represented by the participants' responses to the IPAQ questionnaire (see Table 2, below). None of the participants described themselves as having engaged in high levels of physical activity, and less than half (43.8\%) in moderate activity across the domains. Statements were higher for low level activity with up to $85 \%$ engaging in recreational activity. This included occasional weekly recreation such as light swimming or yoga. It should be noted that the IPAQ in its unadapated format was not 
suitable for young adults with ID in a college setting. Questions required a high level of support and contextualization to be understood by the participants. However, the responses provide some guidance for future adaptation, and synthesizing these findings with the adapted and validated version (Taggart et al. 2017) may enable development of an appropriate tool for assessing levels of physical activity in young adults with ID who attend college.

Insert Table 2 here

\subsubsection{Pedometer recordings}

The measures are presented below in Table 3 below, and provide an indication of how far the students were able to consistently remember to wear and record the pedometers, together with how frequently they engaged in ambulatory activity. Although the colleges were only asked to record one week of data, Site B recorded additional weeks. These have been included, as they provide a broader range of data.

Insert Table 3 here

The mean number of days recoded per week from the combined sample was 1.96 (SD 1.1, range 0-3), suggesting that three recorded days per week was challenging to achieve. The levels of wearing and recording may have increased post-intervention. However, the discussions in the focus groups suggested that there were substantial areas of difficulty. 
The combined mean number of steps was 4485.7 (SD 3211). Melville et al. (2015) reported a baseline step count of 4780 (SD 2432) steps per day in a sample of 102 people with ID, and a $t$-test found the difference between this and the findings above to be nonsignificant $(\mathrm{p}=0.6287)$. Therefore, it is likely that this level of activity is representative of people with ID. However, it is notable that the mean age of the participants was 46.3 years (SD 12.9), compared to mean 20.9 years (SD 5.02) in the present study. The similar level of activity between samples is therefore counterintuitive, as it would be reasonable to predict a higher level of activity in a younger age group.

\subsection{Accessibility and acceptability: Focus Groups}

An overview of themes and subthemes is presented below in Figure 2, below.

Insert figure 2 here

\subsubsection{Theme 1: Acceptability and impact}

The first theme emerging from the focus groups was "Acceptability and impact". "Positive feedback for Walking Away" represents statements which reflect the students' and staff's positive recollections. In "Impact of the course", examples of the apparent impact of keymessages are reflected by descriptions of behaviour change following the delivery of the program. 


\section{Positive feedback for Walking Away}

There was consensus that WA had been an enjoyable experience overall. Students appeared to value the importance of learning about their bodies, and ways in which they could maintain a healthy lifestyle. Ali, an articulate 19-year-old man in Site A, spoke about his learning experience:

Ali: "They were quite brilliant, 'cause you learned all about your body ... and how you can keep on doing regular exercise..."

Students in Site B also spoke positively about their experience of attending the sessions, particularly in relation to components involving role play. One session involved a demonstration of increased risk of diabetes due to multiple risk-factors using an analogy within role play. Students in Focus Group 1 discussed their reasons for appreciating this activity:

Steven: "It gave us a wee laugh"

It is possible that the appeal of this activity was limited to humour. However, as Elspeth pointed out in the lecturer and support staff focus groups, humour may nonetheless have aided learning retention. 
Elspeth: "I think anything that's got a bit of humour, a bit of fun... that definitely sort of sticks in their mind."

Active learning was also considered as being well received by the staff. Here, students were actively engaged in learning exercises such as arranging activity cards into order and identifying food packaging labels. Scott and Margaret, lecturers from Edinburgh College who had attended all the Walking Away units, described examples of these:

Scott: "I liked it when we had the different cards lined up ... that worked really well."

Margaret described this activity as an "interaction", suggesting that the educator and students were responding to each other. Scott praised the fact that the students were encouraged to engage with materials by moving around the room, and suggested that it was good that the students "recognised things" from everyday life, which may have made the activity more meaningful for the students.

\section{Impact of Walking Away}

A session which explored food choices appeared to have made an impact on Anita, who seemed to have acted upon an activity where food labels were checked for fat types and content: 
Anita: "I have ... healthy stuff now... I look at the back of my prawns and my salad."

Anita's apparent healthy eating awareness was confirmed by lecturers, and it was highlighted that other students had engaged in this awareness during break-times. Susan, whose duties involved supporting the students at these times, observed some apparent impact from the program on the students' food choices, describing an "energy change". Elspeth followed on from this by describing a need for further reinforcement to sustain this enthusiasm:

Elspeth: "I think it would need to be reinforced ... some of them were talking about changing their behaviour but haven't quite got there yet."

This raises the question of how far the impact of WA could be sustained over time without reinforcement. Furthermore, not all students were responsible for grocery shopping, and this may have detracted from the relevance of this unit:

Kerry: Well, I don't buy the stuff from the shops ... My Dad goes to Tesco's to get food for dinner and things

Kate suggested that the students have limited opportunities for autonomous food choices. Margaret additionally described the students as either "very dependent" on others or 
resistant to change regarding dietary choices. This component of WA may therefore have mixed applicability to young people with ID.

Impact was also described in relation to physical activity. Beth, a 44-year old woman in Focus Group 2, had decided to walk rather than take the bus to college, to increase her daily step count:

Beth: “...I walk every day. I walk into the college in the morning and I walk home now instead of the bus."

It was unclear whether Beth's efforts were due to messages of the program, the pedometer alone or other factors. However, the WA messages of diabetes risk factors and ways of increasing activity within daily routines may have influenced this change. Kate and Margaret discussed this:

Kate: "I think she was impressed at the number of steps ... She was interested in seeing the number of steps she took..."

From the participant statements is it possible to conclude that there was an overall sense of enjoyment and acceptability of the program together with a willingness to take on board some of the key-messages and act upon them. In places these were affirmed by the lecturers and support staff, though the need for further reinforcement was identified. 


\subsubsection{Theme 2: Understanding Course Content and Procedure}

This theme represents the students' understanding of WA content, as indicated by the students' descriptions, and the perceptions of the staff. Understanding is represented in relation to key-messages and information, as well as to the wider study process.

\section{Understanding of Content}

Education on diabetes was delivered using visual aids, role play, and analogies to explain diabetes concepts. The students' ensuing understanding seemed mixed. Some students appeared to recognise concepts when shown WA resources as prompts:

Ali: "Oh yeah! The stomach, the muscles, the pancreas and all that."

Students also demonstrated an understanding of a visual timeline which showed a progression of diabetes risk. Nick and Michael appeared to understand this progression:

Michael: "No diabetes. If we hit that, good!"

Nick: "And then - at risk."

Michael: "And then at the red you've got it."

Michael appeared to understand that the coloured bar, which moved from green to red, indicated the increased risk of diabetes. However, it is not clear if he understood that this 
could be achieved through reducing risk factors. Participants did not recall risk factors when asked, which may indicate limitations to their understanding.

The physical activity unit did not appear to have been clearly understood by the students from Site A, who did not seem to recognise components when given cues. However, the students in focus group 2 appeared to have understood the message concerning the benefits of physical activity, recalling various examples of physical activity. With regard to the pedometers, Anita demonstrated an understanding of the reason for measuring step counts:

Anita: "Because it's good to see how many steps you've done..."

Students in both groups enthusiastically recalled a model demonstrating overcoming barriers to behavioural change, and appeared to have some understanding of its messages. Steven and Kerry seemed particularly drawn to this:

Steven: "Yeah, I liked that one ... it's a bit like motivating yourself." Kerry: "I also felt the same."

Steven and Kerry had both actively engaged in this activity during the unit. However, it is unclear from their statements whether it was just this aspect of the model that was understood, or whether there was a broader understanding of health messages. The food content unit, which focussed on saturated fats, appeared to have been understood by Michael: 
Michael: "It's the higher contents and the lower contents. Healthy."

Overall, the statements of the students suggested that there was some recollection and understanding of the Walking Away program, but with evident limitations. This leads on to the next sub-theme, in which barriers to learning are explored.

\section{Barriers to Understanding}

A difficulty for students was the use of analogies. Ali appeared to recollect and enjoy the session describing blood glucose, but he and Steven seemed unaware of the link between this and the analogous image when asked:

Steven: "Not a clue."

Ali: "Don't have a scoobie."

The analogy was used throughout the units which could have made it easier to learn and subsequently remember, yet this did not appear to be the case. Joseph, a lecturer at Glasgow college, discussed this issue: 
Joseph: "Anybody who's more towards the autistic side probably won't get it it's like this is this thing, and that's that thing. And it's different."

The lecturers from Site A also commented on the analogies, and Scott felt they needed to be more "explicit". Vocabulary seemed a barrier to learning, for example "insulin" seemed a difficult word for the students to learn, with one student answering "insulation" when given a cue. Unfamiliar words and phrases may have been a barrier for the students, and future adaptations could simplify terminology. This was echoed by Irene from Site B who described the language as a "bit too advanced". It was suggested that there should have been a broader focus on health and wellbeing, rather than diabetes specifically:

Margaret: "I don't think they need to understand the level of detail about how diabetes works [Lorna: "They never understood it anyway." Kate: "It's too complicated"] ... It just needs to be a part of being healthy..."

Kate and Lorna appeared to agree with Margaret that a general healthy lifestyle and walking message as the information on diabetes was too complex.

\section{Understanding study procedure}

This subtheme represents the student participant's understanding of the study's procedure, including consent, right to withdraw and confidentiality. There appeared to be a strong 
understanding of consent, with several voices affirming the understanding that participation was voluntary:

Sean: "Yeah we felt like it was out choice, definitely."

In the staff focus groups, Susan followed commented on the accessibility of the student participant information sheets:

Susan: "They were really user friendly because you used pictures and it was done in a way that was accessible to our students."

However, Margaret and Kate expressed the difficulties they encountered in trying to describe the different elements of the study. The information sheets which had been received in advance, did not appear to have helped to clarify these descriptions. Scott described some ambiguity around consent:

Scott: "... to say that you've got a choice to be a part of this or not ... usually we try and encourage people to always take part anyway..." 
The lecturers and support staff may therefore have felt that it was difficult to encourage participation without coercion. Perhaps due to this, the students appeared to have understood that participation was voluntary, but not all their right to withdraw from the study.

Students appeared to have understood and retained their understanding of confidentiality and anonymity, and what these meant in relation to the study, with Catriona articulating that "only the people that are in it know". Except for right to withdraw, the students seemed to have an overall strong understanding of the study procedure. The pictures together with verbal explanations by the researcher and lecturers appeared to assist the students with their understanding.

\subsubsection{Theme 3: "Issues and solutions"}

The final theme represents issues with WA as perceived by the students and lecturers, who offer solutions to some of the issues described thus far. These regarded delivery, materials and resources as well as with wearing and recording the pedometers.

\section{Delivery Suggestions}

The students seemed aware that familiar teaching methods could have facilitated their learning. Catriona and Nick suggested the use of phonics in relation to learning new vocabulary, as well as presentation on Smartboards, which Catriona highlighted was something they were "used to since school".

The lecturers had alternative suggestions regarding delivery, including incorporating the program into existing modules. 
Patricia: "It could be brought into some of the modules we do like Selfawareness or Into work..."

Through suggesting that the program be delivered as part of existing modules, it was implied that the lecturers could deliver WA. A second alternative to outside educator delivery was suggested by Susan, in Site A:

Susan: "...peer educators ... My experience is that young people always identify with other young people"

Susan discussed the benefits of peer delivery, such as potential for receptivity due to perceived age-relatedness. There was a less positive discussion around this at Site A. Kate and Margaret interpreted "peer-led" as student-led, and seemed to feel that although some students may listen more to their peers, this "wouldn't make them understand more". There were reservations about the level of support potentially required for peer delivery in both sites.

A solution to the issue of understanding analogies was offered by Margaret, using cards to make a more explicit link:

Margaret: "So you could've ... cards that stood up ... risk factors that were like that." 
Additional time was suggested for other components of the program, particularly where participants were encouraged to make written plans for increased walking, an activity which required higher support for many of the students, as Kate and Scott highlighted when asked about this activity:

Kate: "I don't think we spent long enough ... [Scott: "Yeah I don't think it was long enough."] ... going through them with people..."

Other practical solutions from lecturers and support staff included routine and repetition, further active learning and video recaps between sessions. In Site A, Scott suggested practical activities to test learning:

Scott: "...there was no real chance to test their understanding ... if you do a sheet where they have to cut out and match the words you can see who's understanding it better and who needs a bit of help."

It was apparent that Joseph and Susan felt that they had to adapt within classes, which they described as "very diverse". Tailored support was required to avoid exclusion. Margaret also discussed the need for a tailored approach to educating:

Margaret: "You might have the same subjects every year but your approach has got to be different depending on [who's] put in front of you." 
These suggestions may reflect techniques used within a further education college and may therefore be typical of ongoing education rather than a brief program. Such techniques may be necessary to ensure successful learning, and the structure of programs such as WA may need to be adapted for delivery in this setting so that they can be incorporated.

\section{Materials Suggestions}

In this sub-theme, the participants' thoughts on the WA materials are represented. In both focus groups the size of some of the materials was discussed, and the Smartboard suggestion was raised again. At Site A, Lorna discussed Boardmaker, a software tool for creating images to support communication:

Lorna: "I don't understand why if they're going to work with people with learning disabilities they don't use Boardmaker."

Future adaptations of the WA could involve supporting such materials alongside the WA resources, potentially facilitating the students' learning through using a familiar format. Anita mentioned internet resources: 
Anita: "Maybe seeing some pictures on the internet [to] tell you whether you've got diabetes."

Anita seemed familiar with using the internet to access information but did not describe how this could work in relation to the Walking Away materials. In the lecturers focus group, Scott discussed the recording of pedometer steps in relation to the internet:

Scott: "...they could record their steps online ... and they could record things like how much they walked..."

Accessing and using the internet may be a popular interest for some young students with ID, and incorporating this as an activity may increase WA's accessibility for people with ID.

The final issue identified by the students was wearing and attaching pedometers. Catriona complained that it had "digged in to my skin", which may have made her and others less likely to wear the pedometer over time. Students also found the display "too small" and "too dark", and the opening mechanism was "quite tricky". Kate and Margaret in Edinburgh College also reported difficulties in assisting students to wear the pedometers:

Kate: "... sometimes it was a little bit of a hoo-hah getting one or two of them to even put it on" 
Lorna suggested that numeracy difficulties were also a barrier in recording the pedometers. The students may have struggled to record pedometer readings without additional support. They may also have been used to other devices, which may have influenced their suggestions for alternatives to the pedometers, including a Nintendo DS, a Smartwatch and Fitbit. However, there were also concerns from staff about these devices and it was felt that additional support would be required, as well as supervision of internet content access. Further research into the validity of these devices would also be required.

\section{Discussion}

The mean participant age in the present study was 20.9 years, substantially lower than the mean age of participants in mainstream T2D preventative studies ( 54.5 years) reviewed by Maine et al. (2018b). Therefore, the strategy of recruiting participants in a further education setting was a successful approach in terms of targeting a younger age group.

The physiological data highlights that waist circumference and BMI levels were risk factors for participants, according to NHS guidelines (NICE, 2018). This could potentially lead to the risk of developing illnesses and chronic diseases such as diabetes. These findings support the extant literature on the health of people with ID, and further highlight the need for appropriate interventions.

The IPAQ proved difficult to use with people with ID in a further education setting as the questions did not account for lifestyles which were predominantly college-based. However, the IPAQ questionnaire highlighted that for a young age group, the participants did not engage in activity which could be described as "vigorous", and in small amounts of "moderate" activity. Participants also engaged in low levels of physical activity, consistent 
with the findings of McKeon et al. (2013), who used the IPAQ alongside a physical activity monitor armband and found there to be no sustainable high physical activity intensity levels amongst men with ID in younger age groups (19-39 years). It has therefore been important to evaluate the potential for an intervention which aims at increasing physical activity in this population.

The positive response from the students in the focus groups appeared to be partly linked to relationship-building. The lecturers suggested that activities where humour and role play was integrated had been enjoyed the most, perhaps also highlighting the importance of relationships, as these activities promoted interaction between the participants, researcher, and the lecturers who supported the activities. The first author had made several visits prior to delivering the Walking Away program, which created a sense of familiarity, as recommended by Kaehne and O’Connell (2010).

The students did not appear to have understood the overall program in depth. Lecturers commented on the complexity of the language and the use of abstract analogies, suggesting these were not likely to have been understood by people with ASD or Asperger's Syndrome. People with ASD tend to make literal interpretations of analogies and metaphors (Tager-Flusberg, 1999), which may have therefore hindered understanding. Statements in the students' focus groups did not indicate a strong understanding and the areas which the lecturers highlighted as problematic mirror those where the students struggled to recall or describe content.

It is possible that where unsuitability was perceived, this may have reflected attitudes towards the students' capacity to learn and understand, rather than towards the course content and materials. This perceived limitation of the students rather than the program was also apparent when a lecturer suggested that some students would be too "set in their ways" to 
change. Attitudes towards behavioural change have been studied in relation to Ajzen's (1991) Theory of planned behaviour (TPB), which suggests that beliefs and attitudes can impact upon the behaviour of self and others. Were a larger trial assessing the Walking Away program for people with ID to take place, there would be a greater number of lecturers and subsequently a wider range of attitudes. It may therefore be important to use the lens of the TPB as an analytical tool, so that the impact of lecturer attitudes on student participation, engagement, and retention could be evaluated.

Participants were invited to reflect on their own personal risk factors, and it was apparent that some of the participants had multiple risk factors. In the mainstream Walking Away RCT (Yates et al., 2016), recruitment selection was based on individuals above the $90^{\text {th }}$ percentile of the Leicester Practice Risk Score (Gray et al., 2012), where age, ethnicity, gender, family history of diabetes, antihypertensive therapy, and BMI were used as factors to calculate risk. Future trials of Walking Away aimed at people with ID could consider recruitment based on this tool. In the present study, participants were not recruited on the basis of being at risk, and the perceived consequences of risks may therefore have been less acute. The potential for positive illusory bias in people with ID (Salaun et al., 2014) may also have reduced the participants' perceived risks and consequences as their healthy behaviours may have been overestimated.

The vocabulary was seen by some of the lecturers as linguistically complex and therefore difficult to retain. However, the Precontemplation stage in Prochaska and DiClemente's (1983) Transtheoretical model (TTM) suggests that the appropriateness of learning materials can impact upon progression from this stage to the next, and it is therefore essential that information guiding change is tailored to the needs of participants. The TTM was also mirrored in one of the activities in the Physical Activity session, where a diagram 
depicted stages of motivation, including facing and overcoming relapses. Although there was an enthusiastic recall from participants, understanding seemed superficial. Further work may be required to evaluate the stages of change model for people with ID, in order to ascertain its appropriateness.

The dietary choices module seemed suited to participants in this setting, though could potentially be modified by incorporating discussion of lunchtime choices. A concern later raised by the lecturers and teaching support staff was the availability and accessibility of vending machine food. These concerns have implications for wider policy and practice regarding the prominence of machines selling snacks with high sugar and saturated fat content. A recent study on the prevalence of obesity in healthcare professionals by Kyle et al. (2017) has led to the banning of vending machines selling sugary snacks and drinks by an NHS trust in England (Telegraph, 2018). A similar approach was undertaken by a T2D prevention program in a school setting (Saksvig et al., 2005), which led to significant improvements in dietary habits and knowledge. Such a measure may therefore be effective in a further education setting, although this raises an issue of choice and autonomy.

Suggestions were made for the materials to be presented via the Smartboard, which was a familiar format to the students. Internet-based resources were also suggested, which the lecturers acknowledged was an approach used to enable independent learning, where students could actively search information on a given topic. This technique could potentially be used to learn about diabetes resources. Accessible information on diabetes is available at the Diabetes UK website (Diabetes UK, 2014). There may be limitations to this approach, as students in higher education settings from diverse backgrounds may have differing levels of digital literacy (Selwyn, 2010). However, internet-based interventions such as Wu et al. (2011) and Jennings et al. (2014) led to significant improvements in diabetes self- 
management in the mainstream population, demonstrating the reach of such approaches. Supplementing a group program with internet-based activities may extend scope and inclusivity.

As the discussions moved on to the physical activity component of the programme, participants focussed primarily on issues with the pedometer, rather than guidelines on goal setting, although there had been some praise for a model which looked at overcoming barriers. The Yamax Digiwalker SW200 appeared to have been unfit for purpose for people with ID. Alternatives were suggested, such as Fitbits, and a Nintendo DS. Limitations with the use of pedometers to record ambulatory activity with people with ID have already been reported in the literature (Temple and Stanish, 2009). However, the focus groups in this study helped to identify some of the complexities of the issues in the FE college setting, particularly around the challenges of sustaining support beyond the campus environment. There has been a recent growth of studies exploring the use of technology assistance in improving fitness. Mobile phone apps have been evaluated, based on the now common prevalence of Smartphones. A recent review by Direito et al. (2014) reported a range of paid and unpaid apps available which target physical activity and diet. However, evidence for their efficacy was limited, and the apps lacked many important behavioural change components such as overcoming relapses and setting goals. Validity of these apps for people with ID to use would therefore need to be evaluated. Furthermore, whilst there was an assumption that young people are likely to have digital literacy and access to technology (Selwyn, 2010), this may not be the case for people with ID due to social-economic inequalities (Emerson and Baines, 2010). Lecturers commented that many students do not have Smartphones. In the mainstream population, The Fitbit has been validated when assessed alongside previously validated accelerometers (Brewer, Swanson, and Ortiz, 2017) 
and may be an appropriate tool, though further validity assessment for people with ID may need to be conducted.

The lecturers raised the possibility of a long-term delivery of the Walking Away program. This could enable greater opportunities for additional support and subsequently higher participation, as well as continued reinforcement of key messages. As potential participants would already be in attendance at the colleges, time off work or other life schedules and transport costs may not be concerns to the extent reported by Taggart et al. (2017), and Coates et al. (2017), where interventions were delivered in primary care settings. An analysis by Gillet et al. (2010), found DESMOND to be cost-effective in a primary care setting, and WA costs may be lower in an educational setting. An additional option would be to train lecturers to deliver the WA curriculum, which would have the advantage of using their teaching expertise and relationships with the students and enable them to build WA into their existing modules.

Another lecturer suggestion was towards tailoring the program to the needs of individuals. Whilst most of the lecturers advocated this, there were conflicting suggestions of narrower participant selection aimed at those who were likely to be able to engage with the materials and make behavioural changes. It is possible that students who struggle to understand and engage with the program are more likely to have a lower health literacy, and subsequently be in greater need of diabetes education. Another potential benefit of wider inclusion is that people with ID who are more physically active could act as role models with the program, and could "buddy-up" with less active peers, similar to the suggestion by people with ID in Hale et al. (2011). However, social stigma and social comparisons between people with ID are important to acknowledge (Paterson, McKenzie, and Lindsay, 2012). Wide inclusion may help to reduce stigma and provide opportunities for positive social 
comparisons, thus enhancing Self-efficacy through "Vicarious experiences" (Bandura, 1977). However, it should also be noted that some of the students were categorised as being of a healthy weight and engaged in regular recreational physical activity prior to implementation of the Walking Away program. These students may therefore have been at lower risk of developing diabetes and potentially less motivated to participate in the program, and exclusion of these students may not be inappropriate.

Peer education was raised by the lecturers as a potential delivery modification and was discussed in relation to peers with ID within classes, and peers without ID of a similar age group, and could provide an opportunity for "Vicarious experiences". Some of the lecturers suggested that additional support and planning would be required, and there were doubts over the willingness of students to make peer-influenced behavioural changes. Once again, this may reflect attitudes of perceived limited capacity and disposition (Ajzen, 1991), although it is possible that these concerns were realistic and pragmatic.

\section{Limitations}

The fidelity of WA was not measured. As the program was delivered by the researcher, this was not possible as there may have been potential for bias. An alternative could have been to structure the interview schedule for the lecturer focus groups so that the fidelity of WA was a focal point. However, there was not a consistent attendance from lecturers throughout the program, so it may have been challenging to obtain an overall appraisal of fidelity. In addition, the values and philosophies of WA are drawn from the DESMOND program, and this appraisal has already been conducted by Taggart et al. (2017). The focus in the present 
study was instead on acceptability and accessibility of the materials to people with ID in further education colleges, which has provided an original contribution to knowledge.

A second limitation is that the effects of WA were not evaluated using repeated measures. These could potentially have included measuring changes in ambulatory activity and in HbA1c levels, assessed at intervals over 12 months. A challenge in this approach would have been in obtaining an adequate sample size to demonstrate a significant change in these levels. The mainstream WA study (Yates et al., 2016), recruited a powered calculation sample of 808 participants; this would not have been possible in the present study due to pragmatic constraints. Feasibility of conducting a study is an important step prior to conducting a large trial with the resources to overcome these pragmatic challenges, and such a step has been a key focus of the present study.

Finally, although recruitment can be described as successful in that $92 \%$ of participants who were invited to participate agreed to take part in the study, only two of six invited colleges agreed. This may be indicative of the recruitment challenges in the educational sector. However, as the first two colleges that were approached provided a sufficient sample size for the study design, it was not necessary to pursue recruitment vigorously in additional colleges, and multiple follow-ups were not made.

\section{Conclusion}

It can be concluded that the main misgivings of the lecturers were directed at the present, unadapted version of the Walking Away program, and that they believed a version 
incorporating their suggestions could be viable. Whilst a version of the program in which lecturers can take ownership has been suggested, support and guidance may be required to ensure successful planning and implementation. This raises the question of whether lecturers should undertake the Walking Away educator training program in its present format and then make subsequent adaptations of their own, or whether an adapted version of the training program should be developed which incorporates the suggestions of the lecturers in the present study. An adapted version of the training program could be piloted with groups of lecturers to validate its suitability before a larger implementation. This pilot could be assessed by an expert panel and delivered to staff from multiple higher education organisations so that a range of teaching approaches and wider curriculums are represented.

\section{References}

Ajzen, I (1991). "The theory of planned behavior". Organizational Behavior and Human Decision Processes 50 (2): 179-211

Bandura, A. (1977). Self-efficacy: Toward a unifying theory of behavioral change. Psychological Review, 84(2), 191-215

Brewer, W., Swanson, B. T., \& Ortiz, A. (2017). Validity of Fitbit's active minutes as compared with a research-grade accelerometer and self-reported measures. BMJ Open Sport \& Exercise Medicine, 3(1), e000254. doi:10.1136/bmjsem-2017000254

Chaiken, S., (1987) ‘The heuristic model of persuasion' In M P Zanna and, J M Olson and CP Herman (Eds), Social influence: The Ontario symposium, Hillsdale, NJ: 
Erlbraum. 5: 3-39

Coates, V., Slevin, M., Carey, M., Slater, P., \& Davies, M. (2017). Declining structured diabetes education in those with type 2 diabetes: A plethora of individual and organisational reasons. Patient Education and Counseling. http://doi.org/10.1016/j.pec.2017.10.013

Contento, I. R., Koch, P. A., Lee, H., \& Calabrese-Barton, A. (2010). Adolescents demonstrate improvement in obesity risk behaviors after completion of choice, control \& change, a curriculum addressing personal agency and autonomous motivation. Journal of the American Dietetic Association, 110(12), 1830-9. doi:10.1016/j.jada.2010.09.015

Davies, M. J., Heller, S., Skinner, T. C., Campbell, M. J., Carey, M. E., Cradock, S., Khunti, K. (2008). Effectiveness of the diabetes education and self-management for ongoing and newly diagnosed (DESMOND) programme for people with newly diagnosed type 2 diabetes: cluster randomised controlled trial. British Medical Journal (Clinical Research Ed.), 336(7642), 491-5. doi:10.1136/bmj.39474.922025.BE

Diabetes UK (2017). Diabetes: the basics. what is diabetes? https://www.diabetes.org.uk/Diabetes-the-basics/.

Dunkley, A. J., Tyrer, F., Doherty, Y., Patel, N., \& Spong, R. (2017). Development of a multi-component lifestyle intervention for preventing type 2 diabetes and cardiovascular risk factors in adults with intellectual disabilities, (January), 1-10.

http://doi.org/10.1093/pubmed/fdx067

Emerson, E. and Baines, S., (2010) Health Inequalities \& People with Learning Disabilities in the UK: 2010, Learning Disabilities Observatory Retrieved from https://www.improvinghealthandlives.org.uk 
Faro, B., Ingersoll, G., Fiore, H., \& Ippolito, K. S. (2005). Improving Students’ Diabetes Management Through School-based Diabetes Care. Journal of Pediatric Health Care, 19(5), 301-308. doi:10.1016/j.pedhc.2005.03.004

Gillies, C. L., Abrams, K. R., Lambert, P. C., Cooper, N. J., Sutton, A. J., Hsu, R. T., \& Khunti, K. (2007). Pharmacological and lifestyle interventions to prevent or delay type 2 diabetes in people with impaired glucose tolerance: systematic review and meta-analysis. British Medical Journal, 334(7588), 299-299. doi:10.1136/bmj.39063.689375.55

Gray, L. J., Khunti, K., Edwardson, C., Goldby, S., Henson, J., Morris, D. H., ... Davies, M. J. (2012). Implementation of the automated Leicester Practice Risk Score in two diabetes prevention trials provides a high yield of people with abnormal glucose tolerance. Diabetologia, 55(12), 3238-3244. http://doi.org/10.1007/s00125-012-2725-8

Hale, Leigh A.; Trip, Henrietta T.; Whitehead, Lisa; Conder, Jenny; (2011) Self-management abilities of diabetes in people with an intellectual disability living in New Zealand. Journal of Policy and Practice in Intellectual Disabilities, Vol 8(4), Dec, 2011. pp. $223-230$

Hinckson, E. A., Dickinson, A., Water, T., Sands, M., \& Penman, L. (2013). Research in Developmental Disabilities Physical activity, dietary habits and overall health in overweight and obese children and youth with intellectual disability or autism. Research in Developmental Disabilities, 34(4), 1170-1178. http://doi.org/10.1016/j.ridd.2012.12.006

Jennings, C. a., Vandelanotte, C., Caperchione, C. M., \& Mummery, W. K. (2014). Effectiveness of a web-based physical activity intervention for adults with Type 2 
diabetes-A randomised controlled trial. Preventive Medicine, 60, 33-40. doi:10.1016/j.ypmed.2013.12.011

Kaehne, A., \& Connell, C. O. (2010). Focus groups with people with learning disabilities, Journal of Intellectual Disabilities. 2010 Jun;14(2):133-45. doi:

$10.1177 / 1744629510381939$.

Kyle, R. G., Wills, J., Mahoney, C., Hoyle, L., Kelly, M., \& Atherton, I. M. (2017).

Obesity prevalence among healthcare professionals in England: a crosssectional study using the Health Survey for England. BMJ Open, 7(12), (e018498). doi:10.1136/bmjopen-2017-018498. ISSN 2044-6055

Leventhal, H., Meyer, D., \& Nerenz, D., (1980). The common-sense representation of illness danger'. In Rachman, S. (Ed.) Contributions to medical psychology, New York, Permagon Press. 2: 7-30

Laatikainen, T., Dunbar, J. a, Chapman, A., Kilkkinen, A., Vartiainen, E., Heistaro, S., Janus, E. D. (2007). Prevention of type 2 diabetes by lifestyle intervention in an Australian primary health care setting: Greater Green Triangle (GGT) Diabetes Prevention Project. BMC Public Health, 7, 249. doi:10.1186/1471-2458-7-24

Heideman, W. H., de Wit, M., Middelkoop, B. J., Nierkens, V., Stronks, K., Verhoeff, A. P., \& Snoek, F. J. (2015). Diabetes risk reduction in overweight first degree relatives of type 2 diabetes patients: Effects of a low-intensive lifestyle education program (DiAlert) A randomized controlled trial. Patient Educational and Counselling, 98(4), 476-483. doi:10.1016/j.pec.2014.12.008

Maine, A., Brown, M. J., Dickson, A., \& Truesdale, M. (2018a). An evaluation of mainstream type 2 diabetes educational programmes in relation to the needs of people 
with intellectual disabilities: A systematic review of the literature. Journal of Applied Research in Intellectual Disabilities, (November 2017), 1-24. http://doi.org/10.1111/jar.12544

Maine, A., Dickson, A., Brown, M., \& Truesdale, M. (2018b). The experience of type 2 diabetes self-management in adults with intellectual disabilities and their caregivers: A review of the literature using meta-aggregative synthesis and an appraisal of rigor. Journal of Intellectual Disabilities 15(1) http://doi.org/10.1177/1744629518774172

McCurley, J. L., Fortmann, A. L., Gutierrez, A. P., Gonzalez, P., Euyoque, J., Clark, T., ... Gallo, L. C. (2017). Pilot Test of a Culturally Appropriate Diabetes Prevention Intervention for At-Risk Latina Women. The Diabetes Educator, 43(6), 631-640. http://doi.org/10.1177/0145721717738020

Melville, C. A., Mitchell, F., Stalker, K., Matthews, L., McConnachie, A., Murray, H. M., ... Mutrie, N. (2015). Effectiveness of a walking programme to support adults with intellectual disabilities to increase physical activity: walk well cluster-randomised controlled trial. International Journal of Behavioral Nutrition and Physical Activity, 12(1), 125. http://doi.org/10.1186/s12966-015-0290-5

Melville, C. A., Cooper, S. A., Morrison, J., Smiley, E., Allan, L., Jackson, A. Mantry, D. (2008). The prevalence and incidence of mental ill-health in adults with autism and intellectual disabilities. Journal of Autism and Developmental Disorders, 38(9), 16761688. doi:10.1007/s10803-008-0549-7

McKeon, M., Slevin, E., \& Taggart, L. (2013). A pilot survey of physical activity in men with an intellectual disability. Journal of Intellectual Disabilities, 17(2), 157-67. http://doi.org/10.1177/1744629513484666 
Moore, G., Audrey, S., Barker, M., Bond, L., Bonell, C., Hardeman, W., ... Wight, D. (2014). Process evaluation of complex interventions. Complex Interventions in Health: An Overview of Research Methods, 222

National Institute for Health and Care Excellence (2018). Retrieved from https://www.nice.org.uk/guidance/cg189/chapter/1-recommendations

Paterson, L., McKenzie, K. \& Lindsay, W. (2012). Stigma, social comparison and self- esteem in adults with an intellectual disability. Journal of Applied Research in Intellectual Disabilities, 25, 166-176

Prochaska, J. O., \& DiClemente, C. C. (1983). Stages and processes of self- change of smoking: Toward an integrative model of change. Journal of Consulting and Clinical Psychology, 51(3), 390.

Sacco, W. P., Malone, J. I., Morrison, A. D., Friedman, A., \& Wells, K. (2009). Effect of a brief, regular telephone intervention by paraprofessionals for type 2 diabetes. Journal of Behavioral Medicine, 32(4), 349-359. doi:10.1007/s10865-009-9209-4

Salaun, L., Reynes, E., \& Berthouze-Aranda, S. E. (2014). Adapted physical activity programme and self-perception in obese adolescents with intellectual disability: between morphological awareness and positive illusory bias. Journal of Applied Research in Intellectual Disabilities: JARID, 27(2), 112-124. http://dx.doi.org/10. 1111/jar.12056.

Saksvig, B. I., Gittelsohn, J., Harris, S. B., Hanley, A. J. G., Valente, T. W., \& Zinman, B. (2005). A pilot school-based healthy eating and physical activity intervention improves diet, food knowledge, and self-efficacy for native Canadian children. The Journal of Nutrition, 135(10), 2392-2398. doi:135/10/2392 [pii] ET - 2005/09/24 
SCLD Learning Disability Statistics Scotland, 2017. Retrieved from:

https://www.scld.org.uk/wp-content/uploads/2017/12/2017-Learning-Disability$\underline{\text { Statistics-Scotland.pdf }}$

Schneider, P. L., Crouter, S. E., Lukajic, O., Bassett, D.R. (2003) Accuracy and reliability of 10 pedometers for measuring steps over a $400 \mathrm{~m}$ walk. Med Sci Sports Exerc 2003351779-1784

Scott, H. M., \& Havercamp, S. M. (2016). Systematic Review of Health Promotion Programs Focused on Behavioral Changes for People With Intellectual Disability Systematic Review of Health Promotion Programs Focused on Behavioral Changes for People With Intellectual Disability, (January), 62-76. http://doi.org/10.1352/1934-9556-54.1.63

Selwyn, N., \& Ebooks Corporation. (2010). Education in a digital world : Global perspectives on technology and education. Claremount, W.A.: Ebooks Corporation.

Taggart, L., Truesdale, M., Carey, M. E., Martin-Stacey, L., Scott, J., Bunting B., Coates V., Brown, M., Karatzias, T., Northway R., \& Clarke, J.M. (2017) Research: Educational and psychological aspects Pilot feasibility study examining a structured selfmanagement diabetes education programme, DESMOND-ID, targeting HbAlc in adults with intellectual disabilities. Diabetic Medicine doi: 10.1111/dme.13539

Taggart, L., Coates, V., \& Truesdale-Kennedy, M. (2013). Management and quality indicators of diabetes mellitus in people with intellectual disabilities. Journal of Intellectual Disability Research, 57(12), 1152-1163. http://doi.org/10.1111/j.13652788.2012.01633.x 
Tager-Flusberg, H. (1999). A psychological approach to understanding the social and language impairments in autism. International Review of Psychiatry (Abingdon, England), 11(4), 325-34. http://doi.org/10.1080/09540269974203

The Telegraph: Hospital becomes first to ban all sugary food and drink. Retrieved from: https://www.telegraph.co.uk/news/2018/01/09/hospital-becomes-first-ban-sugary-fooddrink/?WT.mc_id=tmg_share_tw

Temple, V.A. \& and Stanish, H.I. (2009) Pedometer-Measured Physical Activity of Adults With Intellectual Disability: Predicting Weekly Step Counts. American Journal on Intellectual and Developmental Disabilities: January 2009, Vol. 114, No. 1, pp. 15-22.

Walwyn, R. E., Russell, A. M., Bryant, L. D., Farrin, A. J., Wright-Hughes, A. M., Graham, E. H., ... House, A. O. (2015). Supported self-management for adults with type 2 diabetes and a learning disability (OK-Diabetes): study protocol for a randomised controlled feasibility trial. Trials, 16, 342. http://doi.org/10.1186/s13063-015-0832-9

Yates, T., Davies, M., Gorley, T., Bull, F., \& Khunti, K. (2009). Effectiveness of a Pragmatic Education Program Designed to Promote ... Diabetes Care, 32, 1404-1410. $\underline{\text { http://doi.org/10.2337/dc09-0130. }}$

Yates, T., Edwardson, C. L., Henson, J., Gray, L. J., Ashra, N. B., Troughton, J., ... Davies, M. J. (2016). Research : Educational and Psychological Aspects Walking Away from Type 2 diabetes : a cluster randomized controlled trial, 1-10.

\section{http://doi.org/10.1111/dme.13254}

Wu, S.-F. V., Lee, M.-C., Liang, S.-Y., Lu, Y.-Y., Wang, T.-J., \& Tung, H.-H. (2011). Effectiveness of a self-efficacy program for persons with diabetes: A randomized 
controlled trial. Nursing \& Health Sciences, 13, 335-343. doi:10.1111/j.1442-

2018.2011.00625.x

Figure 2: Focus group themes and subthemes

\begin{tabular}{|l|l|}
\hline Theme 1: Acceptability and impact & Positive feedback for Walking Away \\
& Impact of Walking Away \\
\hline $\begin{array}{l}\text { Theme 2: Understanding Course Content and } \\
\text { Procedure }\end{array}$ & Understanding of Content \\
& Barriers to Understanding \\
& Understanding study procedure \\
\hline Theme 3: Adaptation suggestions & Delivery Suggestions \\
& Materials Suggestions \\
\hline
\end{tabular}


Table 1: Participant demographics

\begin{tabular}{|l|l|l|l|l|l|}
\hline $\begin{array}{l}\text { Age } \\
\text { (Mean, } \\
\text { SD) }\end{array}$ & Gender & $\begin{array}{l}\text { Height } \\
\text { (Mean, SD) }\end{array}$ & $\begin{array}{l}\text { Weight } \\
\text { (Mean, } \\
\text { SD) }\end{array}$ & $\begin{array}{l}\text { BMI } \\
\text { Classification } \\
\mathbf{( \% )}\end{array}$ & $\begin{array}{l}\text { Waist } \\
\text { circumference } \\
\text { (Mean, SD) }\end{array}$ \\
20.9 years, \\
5.0 & $\begin{array}{l}\text { Female: } \\
37.5 \%\end{array}$ & $169.2 \mathrm{~cm}$, & $\begin{array}{l}81.9 \mathrm{~kg}, \\
22.9\end{array}$ & $\begin{array}{l}\text { Obese: } 37.5 \% \\
\text { Overweight: } 27 \% \\
\text { Healthy weight: } \\
29.1 \%\end{array}$ & $98.3 \mathrm{~cm}, 21.3$ \\
& $62.5 \%$ & & & & \\
& & & & & \\
\hline
\end{tabular}

Table 2: IPAQ summary

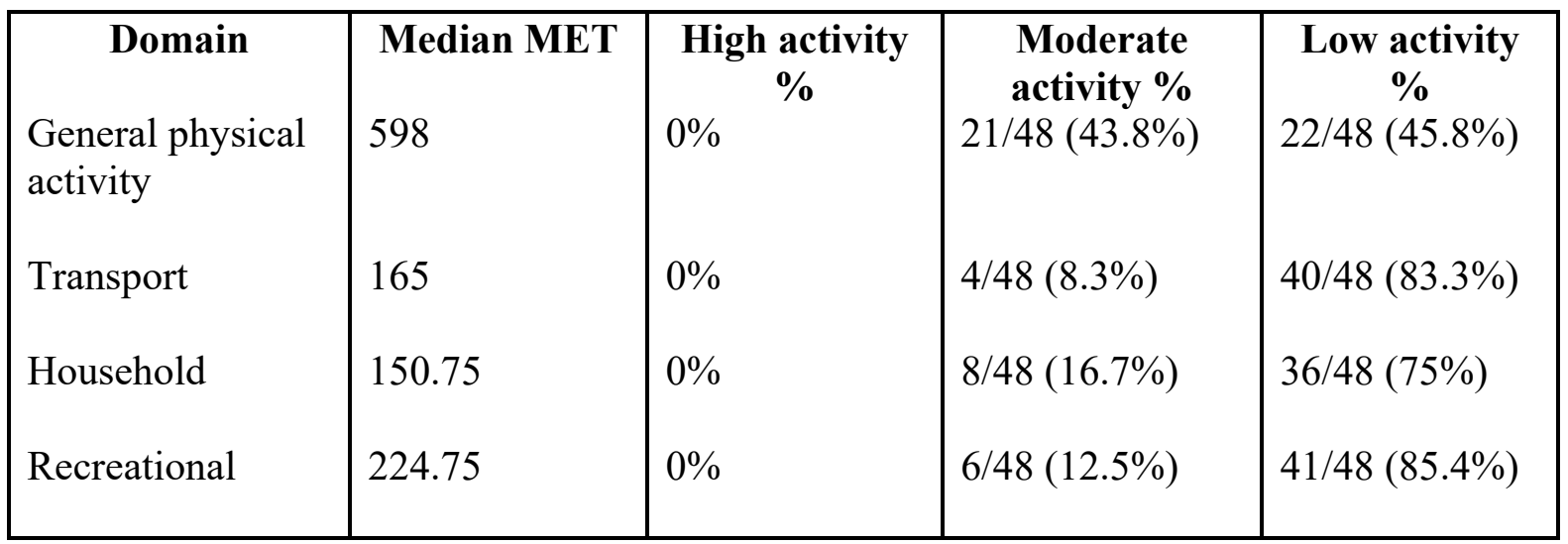

Table 3: Ambulatory activity

\begin{tabular}{|l|l|l|}
\hline Site & $\begin{array}{l}\text { Days recorded (mean days } \\
\text { per week, SD) } \\
1.8,1.1\end{array}$ & $\begin{array}{l}\text { Step count (mean, SD) } \\
\text { Site A }\end{array}$ \\
\hline
\end{tabular}


Site B

2.8, 0.4

$5461.5,2150$

Combined

$1.96,1.1$

4485.7, 3211 